\title{
Digital society, artificial intelligence and modern civil law: challenges and perspectives
}

\author{
Vladimir Kamyshanskiy ${ }^{1,},{ }^{*}$ Dmitry Stepanov ${ }^{2}$, Irina Mukhina $^{3}$, and Dina Kripakova ${ }^{4}$ \\ ${ }^{1}$ Kuban State Agrarian University named after I.T. Trubilin, st. Kalinina, 13, Krasnodar, Russia, vpkam@rambler.ru \\ ${ }^{2}$ Kuban State Agrarian University named after I.T. Trubilin, st. Kalinina, 13, Krasnodar, Russia, o02323@icloud.com \\ 3 North Caucasus Branch of the Russian State University of Justice, st. Levanevsky, 187/1, Krasnodar, Russia, \\ rapkrassnodar@mail.ru \\ ${ }^{4}$ Astrakhan State University, st. Tatishcheva, 20 a, Astrakhan, Russia, kripakova2013@mail.ru
}

\begin{abstract}
The article analyses the problems of civil law regulation of relations arising in the digital society. The property relations, the civil turnover sphere is increasingly shifting to various kinds of electronic platforms. The process was further accelerated by the COVID-19 coronavirus pandemic. The development and application of artificial intelligence technologies bring forward the problem of ensuring safety for humans from the negative impact of such technologies, minimizing threats to their life and health. Due to the virtuality of artificial intelligence as a social phenomenon, a product, a good created by man, the application of traditional legal means to regulate social relations connected with the application of artificial intelligence technologies at present does not provide a full solution to a number of uncertainties arising on the market of goods, works and services. To this end, it is proposed to form a new legal fiction in civil law at the level of scientific doctrine to resolve legal uncertainties arising in civil turnover due to the use of artificial intelligence technologies. It is about formalizing artificial intelligence technology as a subject of law as an "electronic person" or "electronic legal entity" bringing together several legal entities with a special legal personality.
\end{abstract}

\section{Introduction}

The concept of "digital society" and digital rights is a relatively new object of civil rights. The digital economy is an economic activity based on digital technology related to e-business and e-commerce and the electronic goods and services produced and marketed by them. Payments for services and goods in the e-economy are increasingly made in electronic money. The social relations arising from the digitalization of society and the introduction of artificial intelligence technologies have specific characteristics to be considered when choosing the legal means for their legislative regulation. Legal science and the science of civil law face the very difficult task of developing new doctrinal approaches to the legal regulation of social relations associated with the emergence and use of new technologies in the economy and other spheres of life in modern society.

\section{Problem Statement}

Practical problems for lawmakers arise from the lack of new doctrinal approaches in the science of civil law in addressing the problems of civil law regulation of relations arising in society involving artificial intelligence technologies as one of the stages of digitalization of society and the creation of digital space in a post-industrial society. The lack of norms regulating peculiarities of the legal regime for carriers of artificial intelligence, the results of intellectual labour created by them, introduces uncertainty into the regulation of arising relations and comes into conflict with the current legislation in the intellectual law sphere, as well as norms defining the legal status of civil law subjects and the grounds for legal liability.

\section{Research Questions}

The article deals with the legal regulation of relations arising in society as a result of the introduction of digital technology and artificial intelligence. It substantiates the necessity of forming a new legal fiction in civil law that would give the status of a subject of law to a carrier of artificial intelligence. The proposed scientific positions can form the basis for the formation of a new institution of civil law and the further improvement of the current legislation.

\section{Purpose of the Study}

The purposes of the study are to shape the notion of artificial intelligence in civil law scholarship, analyse the characteristics of social relations as an object of legal regulation arising in the digital society, justify the

\footnotetext{
*Corresponding author: vpkam@rambler.ru
} 
feasibility of forming a general classification for carriers of artificial intelligence technology, depending on their degree of autonomy and separateness. Based on the study, it is necessary to develop proposals for further improvement of the current legislation in the digital economy and digital society with the use of artificial intelligence technologies.

\section{Research Methods}

The methodological basis of the study consists of dialectical and general scientific methods of knowledge, including system analysis, synthesis, induction and deduction, as well as special legal methods (formallogical, which allowed to develop a number of conclusions regarding the legal status of the carrier of artificial intelligence in the system of key categories of civil law. The study of the problems of civil law regulation of social relations in the context of the digitalization of society also used abstraction and modelling methods. The comparative-legal and legal foresight method allowed formulating the prospects of legal regulation of relations in a digital society with the use of artificial intelligence technologies.

\section{Findings}

Russia is on the threshold of a new stage in the development of modern civilization, associated with the formation of information space and the development of digital technologies in all spheres of public life. According to V.P. Filimonov, the digital society is a global project that aims to build a new slave society governed by the information and communication technologies based on the use of microelectronics, local and global computer networks that collect, process, generate and distribute information through global telecommunication network systems [1]. It is rather difficult to agree unequivocally with such a categorical definition of the digital society by Valery Pavlovich Filimonov, a publicist, specialist in cybernetics and control systems, academician of the Petrovsky Academy of Sciences and Arts. It is clear that we can avoid a new slave-holding society by placing the advances of modern technology at the service of humanity, by subordinating their use exclusively to human interests through legislation. The continuous growth of the global population and the need to mobilise new resources to sustain it leads to the fact that the e-economy is no longer limited to business and e-commerce and services, but penetrates all areas of human life, including health care, education, science, culture, etc. [2].

The objective reality is that the sphere of property relations, civil turnover, is increasingly shifting to various kinds of electronic platforms. It is such platforms that allow active scientific collaboration at various international and national scientific conferences, maintaining a communication environment even in the forced isolation associated with the COVID-19 pandemic coronavirus infection.
Any digital platform is a collection of interacting hardware and operating systems running various applications and development tools. The Russian market for goods, works and services is increasingly moving to such platforms. There is a transformation of the traditional and tangible property relations familiar to us into a virtual reality where activities take place autonomously, not entirely subject to the human will.

In this context, we should look in more detail at artificial intelligence technologies as objects of civil law regulation. The rapid development of artificial intelligence technology is pushing legal scholars to explore this new phenomenon as an object of study in its own right. The development of artificial intelligence technologies and their introduction into various spheres of social life, production and consumption is a powerful stimulus for the improvement of national and international legislation. The creation of artificial intelligence, the digitalization of the economy and a range of social processes is creating a new social reality that needs to be scientifically understood and legally mediated.

It is equally evident that the legal regulation of relations using artificial intelligence technologies lags far behind the needs of the civil sphere. In this situation, it is only natural that the science of civil law should form its own position and provide answers to the challenges of the times.

In this context, it is worth noting a number of authors who are actively engaged in developing civil law issues of artificial intelligence. Among them, it is necessary to highlight the doctoral dissertation of Peter Mechislavovich Morhat "The legal personality of artificial intelligence in intellectual property law: civil law problems" and the candidate thesis of Evgeny Polikarpovich Sesitsky "Problems of the legal protection of results created by artificial intelligence systems" defended in 2019 and a number of other works [3-6].

The problem is that the social relations arising from the use of artificial intelligence technologies have already formed a number of areas that are now impossible to regulate using the traditional legal means and modes of legal regulation enshrined in the current civil legislation.

In this connection, it is necessary to initially define the essence of the category "artificial intelligence" and then try to apply such traditional institutions of civil law as object and subject of law, subjective right and legal relations, civil liability and tortious capacity to it.

Artificial intelligence is the property of intelligent systems to perform creative functions autonomously and independently of their creators that are traditionally considered the prerogative of humans. An intelligent system can be a technical or software system capable of solving creative problems in a specific subject area, with knowledge stored in its memory. An intelligent system comprises three main units: a knowledge base, a problem solver and an intelligent interface [7].

Today, artificial intelligence has become a global trend. The leading economies are in a race to be the first in this field. One of the most important problems in the development and application of artificial intelligence 
technologies, especially in such sensitive areas as national defence and state security, human life and health, is the problem of excluding any error in its activities, as well as working out ways to compensate for the costs of artificial intelligence errors and to personalize the subjects of such responsibility.

The development and application of artificial intelligence technologies bring forward the problem of ensuring safety for humans from the negative impact of such technologies, minimizing threats to their life and health. Artificial intelligence, for all its power and breadth of possibilities, is just as prone to error as humans. The cost of such mistakes can be very high. For example, errors in the provision of fee-for-service medical diagnoses or consultations to patients by means of artificial intelligence can lead to tragic and sometimes irreversible consequences in the case of a single individual. Artificial intelligence error in national defence and state security could lead to the unauthorized use of nuclear weapons, other weapons of mass destruction and the destruction of humanity.

In this regard, experts in mathematical modelling, concerned with the problems of developing artificial intelligence, see the way out as developing a new generation of artificial intelligence capable of correcting its errors and inaccuracies on its own without human intervention [8]. In itself, the idea expressed by the programmers commands respect and deserves support. It meets the needs of human society. Solving this problem makes it much easier for programmers to work around the bugs of the artificial intelligence built by them. There is no need to retrain such an AI technology carrier for a full "retraining" course based on the identified error.

The emergence of failures in artificial intelligence technologies brings to the fore the problem of personifying the subject of civil liability for harm or loss arising from the use of artificial intelligence technologies. This means that we must be aware that between the malfunctioning of the artificial intelligence and the removal of the malfunctioning in the artificial intelligence, there may be consequences that result in the violation of someone's subjective rights, inability to fulfil obligations assumed, causing harm or damage to citizens or legal entities.

For the structure of the intelligent system, failure could occur in all three of its blocks: the knowledge base, the problem solver and the intelligent interface. These software products have numerous authors developers. Errors in the operation of artificial intelligence could be the fault of individual developers, or of a group of individuals involved in the development of artificial intelligence technology. The errors could also arise irrespective of the fault of the authors of the artificial intelligence technology. For example, it may result from applying an open knowledge base, which is later substantially updated from the original knowledge base generated during the development phase of the intelligent system.

This logically raises the question of who should be held legally responsible for the harms or losses caused by artificial intelligence? Some problems of legal liability associated with the use of artificial intelligence were investigated in the literature by both Russian [9-10] and foreign authors [11]. Legal regulation of integration of artificial intelligence into human society in the context of legal relations that arise in this case requires the solution of such an issue as the distribution of legal liability for harm (damage), losses caused to participants in civil turnover by activities related to the use of artificial intelligence technologies [12].

This problem requires identifying the place of the artificial intelligence carrier among such basic concepts of civil law as "object", "subject" and "legal relationship". In civil law, it is these basic concepts that allow civil law to give certainty to the regulation of property and personal non-property relations. The further assertion that a carrier of artificial intelligence can only be an object of civil rights and not a subject in any way does not reduce the number of problems in the science and practice of civil law.

These problems may well be solved by the formation of new legal fiction in civil law to resolve the legal uncertainties arising in civil turnover due to the use of artificial intelligence technologies. It is about formalizing artificial intelligence technology as a legal fiction, as a legal technique. Legal fiction is known to be a legal device that suggests the existence of a certain fact contrary to existing reality. This recognizes a known non-existent fact as existing. Fiction was already present in the laws of Hammurabi. According to experts, there is no legal order without fictions as legal techniques [13].

At the same time, the literature attempts to make sense of the possibility of giving artificial intelligence the status of an entity as an electronic person. For example, Professor O.A. Yastrebov suggests interpreting the e-person "as a personified unity of rules of law that bind and empower an artificial intelligence (e-person) that possesses the criteria of 'reasonableness'" [14]. Sharing O.A. Yastrebov's position on the admissibility, at least on a doctrinal level, of recognizing the carrier of artificial intelligence technologies as a legal entity, the proposed definition of an electronic legal entity needs critical reflection. It is difficult to treat the e-person as a subject of law as a "personified unity of law" that binds and empowers them. A personified unity of law has a greater right to exist as an independent civil law institution regulating social relations involving a carrier of artificial intelligence.

However, the science and practice of civil law already face a number of challenges that need to be addressed. This refers to the authorship of the results of intellectual activity, paintings and musical works created by an artificial intelligence carrier. As I.V. Ponkin and A.I. Redkina correctly point out, artificial intelligence is capable of creating unique results of an intellectual activity without human involvement [15]. The right of authorship of an AI carrier challenges all the underlying concepts of intellectual property law in relation to the creative element in copyright [16]. There is also a need for legal certainty regarding the fate of the income generated by the artificial intelligence carrier, the subjects of liability for damage caused by the activities of the artificial intelligence carrier due to a malfunction in its operation, and so on. Their solution would 
eliminate the legal uncertainty associated with the use of artificial intelligence technologies. Therefore, we must seek answers to these questions today.

The peculiarity of legal regulation of relations with artificial intelligence technologies relates that human activity involves the use of artificial intelligent systems capable of autonomously exercising certain creative functions apart from the will of a human being. The strategy for the development of legal regulation of relations connected to the use of artificial intelligence technologies requires defining the following directions.

First, it requires determining a list of those technologies that may pose a threat to individuals and society because of their autonomous nature and their inability to fully control human use.

Second, it needs to define the boundary between the carriers of artificial intelligence, which may well qualify as objects, including those relating to sources of increased danger, by classifying the features of their legal regime.

Third, it is necessary to form a scientific doctrine of the carrier of artificial intelligence as a subject of civil legal relations, endowing it with a certain special legal personality. This can be a single artificial intelligence carrier with the conventional name of "e-person" or a combination of them with a specific legal status of "elegal entity" operating in a specific environment on various electronic digital platforms.

In this context, it is time to elaborate the content of a special civil law institute with the title "Participation of Artificial Intelligence carriers in relations governed by civil law" at the doctrinal level as an integral part of a subsection of the civil code with the title defining the legal status of persons acting as subjects of civil law.

This will resolve a number of issues currently in need of resolution. In particular, who owns the copyrights to works created by the robot; who will be held liable for the activities of an artificial intelligence carrier that cause harm (losses) to third parties; what restrictions should be placed on the use of military robots; what should be the legal restrictions and forms of enforcing control over the development of a strong artificial intelligence comparable in intelligence to the human brain.

The use of a robot with artificial intelligence in communication with humans suggests the need to legislate against and limit machine activity of so-called anthropomorphic behaviour (transferring the human image and its properties onto inanimate objects). In this case, it is not enough to have a "red button" to disconnect an artificial intelligence carrier from its power source and prevent it from causing harm or loss to humans, public interest harm or other negative consequences caused by its actions.

For example, we will consider a situation where a robot with artificial intelligence is tasked to represent the state on the board of directors of a joint-stock company with state participation or the interests of a customer when forming the terms of a state contract for the supply of goods for state and municipal needs, or to act as an expert on legislative acts for their anti-corruption nature or limiting competition in markets for goods, works and services. On the contrary, in these cases, the so-called red button in the hands of the person concerned, as well as the manual management of the Russian economy that we have periodically observed, is capable of dashing the long-held expectations of our society.

The successful development of robotics and artificial intelligence is possible if the state has the will and consistency to implement investment and legal policies in the relevant area. In any country, the state is the biggest investor in the national economy. The mass introduction of robots with artificial intelligence into various spheres of social life will lead to significant job losses in government, healthcare, education, banking and the real economy.

Sberbank of Russia, for example, intended to free up around three thousand jobs in 2017 by introducing robot lawyers to handle claims for retail customers. It has plans to move all typical lawsuits to an automated format in the future, which will free lawyers from routine work and focus on resolving complex legal issues [17]. Consequently, we cannot rule out strong opposition to robotization processes and the development of artificial intelligence for a number of social groups in society, including lawyers.

\section{Conclusion}

The adoption of regulations containing peremptory norms seems best in the context of law-making in the development and application of robots with artificial intelligence. Any regulations that contain dispositive principles that open up the possibility of any discretion will serve as a brake on the development of this process and prevent it from becoming irreversible. In the first place, this should apply to the spheres of public life related to the activities of state and local government, courts, the prosecutor's office, health care and education. To alleviate the negative effects of such opposition, it is now necessary to develop state programmes for retraining and retraining of those subject to redundancies due to robotization and to create new jobs for them.

Thus, the rapid development of artificial intelligence and robotics technologies requires appropriate legal regulation of the new social relations that are emerging. Numerous issues currently need to be resolved. In particular, it should be thought about solving the issues of who owns the copyright of the works created by the robot. Equally important is the personalization of responsibility for performance using artificial intelligence technologies. There is a need to develop a system of legal restrictions on the military use of robots, as well as an international system to control the development of strong artificial intelligence technologies comparable in intelligence to the human brain.

\section{References}

1. V.P. Filimonov The digital society and the end of history https://zen.yandex.ru/media/id/5e274bc843863f00acd7e 
d97/cifrovoe-obscestvo-i-konec-istorii-

5f3403d4f8858d5978533028

2. V.P. Kamyshansky, Power of the Law 1, 14-18 (2019)

3. P.M. Morhat, Power of Law 1, 82-95. (2019)

4. P.M. Morhat, Law and Artificial Intelligence: a Monograph. Russian Academy of Intellectual Property. (Moscow, Russia. UNITY-DANA, 2018)

5. M.E. Cheremisinova, Legal status of subjects in virtual space: a monograph (Moscow. Russia. Publishing house "Jurisprudence", 2020)

6. Yu. Tikhomirov, S.B. Nanba The legal concept of robotization: a monograph (Moscow. Russia. Brochure, 2019)

7. A.N. Averkin, M.G. Gaase-Rapoport, D.A. Pospelov, Radio and communications (1992) //http://www.raai.org/library/tolk/aivoc.html\#L208

8. Y. Medvedev, Rossiyskaya Gazeta 207, 9 (2020)

9. T.V. Deryugina., O.A. Inshakova, E.Yu. Malikov, Advances in Intelligent Systems and Computing. Switzerland. Springer International Publishing, 1100, 693-705 (2020)

10. V.P. Kamyshansky, E.Y. Rudenko, E.A. Kolominetz, E.O. Osadchenko, Studies in Computational Intelligence 826, 299-306 (2019)

11. Bublitz Christoph, Wolkenstein Andreas, Jox Ralf J., Friedrich Orsolya, International Journal of Law and Psychiatry 65, 101399 (2019)

12. J. Daar, The Legal Liability Landscape and the Person/Property Divide F\&S Reports URL: https://reader.elsevier.com/reader/sd/pii/S266633412030 0519?token=16A3DD4D2D1796C496AB8AD5A76213 184B4AB105B7046BA58DDBFA46AD76F8A7C2CBA 0398C8413ADAC2045EDC6ECE787 (date of access: 27.02.2019).

13. A.M. Shirvindt, The Significance of Fiction in Roman Law (Moscow, Russia Statut, 2013)

14. O.A. Yastrebov, Proceedings of the Institute of State and Law of the Russian Academy of Sciences 13 (2) (2018)

15. I.V Ponkin, A.I. Redkina, Intellectual Property. copyright and related rights 2, 35-44 (2018)

16. A. BridyStanford Technology Law Review 5, 1-28 (2012)

17. Sberbank Robot lawyers will replace three thousand Sberbank employees (2019), URL: https:/tass.ru/ekonomika/3936662 (date of access: 27.02.2019). 